\title{
MARX, ÉTICA E A CIÊNCIA DA INFORMAÇÃO
}

Marco Schneider

Ricardo Pimenta

SCHNEIDER, Marco; PIMENTA, M. Ricardo. Information Ethics from a Marxian Perspective [dossiê]. International Review of Information Ethics, v.26, n.1, 2017. Disponível em: http:// www.i-r-i-e.net/ current_issue.htm.

\begin{abstract}
* Doutor em Ciências da Comunicação pela Universidade de São Paulo, Brasil. Pesquisador associado do Instituto Brasileiro de Informação em Ciência e Tecnologia, Brasil. Docente permanente do Programa de Pós-Graduação em Ciência da Informação - convênio Instituto Brasileiro de Informação em Ciência e Tecnologia e Universidade Federal do Rio de Janeiro, Brasil. Co-Editor do Vol. 26 do periódico IRIE: Information Ethics from a Marxian Perspective. E-mail: art68schneider@gmail.com.

** Doutor em Memória Social pela Universidade Federal do Estado do Rio de Janeiro, Brasil. Pesquisador associado do Instituto Brasileiro de Informação em Ciência e Tecnologia, Brasil. Docente permanente do Programa de Pós-Graduação em Ciência da Informação - convênio Instituto Brasileiro de Informação em Ciência e Tecnologia e Universidade Federal do Rio de Janeiro, Brasil. Co-Editor do Vol. 26 do periódico IRIE: Information Ethics from a Marxian Perspective.

E-mail: ricardopimenta@ibict.br.
\end{abstract}

E bastante conhecida a mudança paradigmática promovida por Marx em relação à filosofia que o precedeu, privilegiando a práxis (a articulação dialética da teoria e da prática) em relação à teoria pura, sem abandonar o rigor teórico. E o que é a ética senão lidar com a práxis humana? Já para Aristóteles, o objetivo da ética como disciplina filosófica não consiste somente em conhecer o bem, mas em praticá-lo. O mesmo poderia ser dito sobre a ética marxiana, implícita na famosa $11^{a}$ Tese sobre Feuerbach: "Os filósofos até então se limitaram a interpretar o mundo de várias maneiras; resta transformá-lo." Mas transformálo em que sentido? Rumo ao fim da alienação, da exploração e da reificação dos homens e das mulheres.

Nessa perspectiva, a ética em informação aparece como uma das questões teóricas e práticas mais urgentes do nosso tempo. Porque o capitalismo é, mais do que nunca, estruturado com base na apropriação desigual da informação e da competência para lidar com ela, sem as quais nenhum conhecimento sério ou visão de mundo crítica podem ser formados.

A informação é elemento central na disputa pelo poder em qualquer sociedade e a sociedade burguesa não é exceção: informações científicas, informações industriais, informações financeiras, informaç̃es comerciais, informações políticas, informações militares são insumos estratégicos e produtos de alto valor agregado. A relação da informação com a ideia de valor (valor moral, valor poder, valor verdade, valor econômico), portanto, não é nova. A novidade está no regime global de informação hegemônico e em sua relativa abertura digitalmente medida - a despeito da 
forte concentração de controle dos meios de produção das infraestruturas e dos meios de circulação, recuperação, arquivamento e acesso dessas mesmas informações -, que socializa excelentes motores de busca e faz circular uma quantidade enorme de informações relevantes, ao mesmo tempo que sandices, mentiras e informações tendenciosas, numa quantidade talvez ainda mais abissal. Em outras palavras, paradoxalmente, nunca tivemos tamanho número de dados e informações acessíveis a um simples toque do teclado ou dos dedos, ao mesmo tempo em que nunca houve formas de vigilância e retóricas mistificadoras tão ubíquas. O regime global de informação hegemônico, neste sentido, é uma espécie de rua de mão dupla: a cela, mas também a chave.

A perspectiva dos estudos marxianos provê um recurso indispensável ao debate em torno deste cenário, cujo paradoxo parece dar o tom de seus fenômenos e jogos de força. Informar-se para além da alienação, alienar-se pela distopia produzida no excesso e na "má" informação. Algumas questões fundamentais no escopo da ética em informação ganham corpo nessa rede de encruzilhadas, que a fortuna crítica do pensamento marxiano pode ajudar-nos a entender melhor e a evitar armadilhas.

Salvo engano, a Ciência da Informação (como um todo) e o marxismo dialogam pouco no Brasil. Em 2014, por exemplo, foi publicado o livro A informação e o conhecimento sob as lentes do marxismo, organizado por Rodrigo Moreno Marques, Filipe Raslan, Flávia Melo e Marta Macedo Kerr Pinheiro. Alguns autores brasileiros, como os organizadores e autores do livro citado, entre outros, incluindo esta dupla de resenhistas, vêm explorado essa aproximação. Mas ela está longe de ser frequente, até onde pudemos verificar.

Em outra ocasião, Schneider ${ }^{1}$ desenvolveu três hipóteses para essa baixa frequência: o predomínio de tendências instrumentais ou administrativas, na Ciência da Informação brasileira; o desprestígio do marxismo nas décadas de 1990 e 2000; a influência pósestruturalista nas vertentes críticas da Ciência da Informação entre nós.

I SCHNEIDER, M. A. F. Referências cruzadas 2: Marx e a ciência da informação. Encontro Nacional de Pesquisa em Ciência da Informação, v. 16, 2015.
Seja como for, se o diálogo da Ciência da Informação com o marxismo é pouco frequente, a aproximação entre ética em informação e pensamento marxiano promovida pelo dossiê em pauta da International Review of Information Ethics (IRIE) é, ao que saibamos, inédita. Se isto estiver correto, o dossiê traz uma contribuição importante para ambos, bem como para a Ciência da Informação como um todo. Porque a Ciência da Informação é um campo estratégico para a ética e a práxis marxianas hoje em dia, assim como a ética e a tradição marxianas podem ser bons antídotos contra certa inclinação de parte da Ciência da Informação para um tipo de conhecimento mais servil e tecnocrático.

Cabe destacar que, se todos os trabalhos deste dossiê da IRIE tratam da Ética em Informação em uma perspectiva marxiana, alguns deles o fazem apenas de forma implícita ou indireta. É bem verdade que a tradição intelectual marxista não costuma falar diretamente sobre questões éticas. Ao mesmo tempo, a ética está no cerne desta tradição na medida em que ela própria é impensável, sem uma crítica radical da reificação humana, da exploração, da alienação e de um chamado constante, para cada geração, pela sua superação, rumo a novas formas históricas concretas de liberdade, justiça, racionalidade, autodeterminação humana. Assim, de forma explícita ou não, todos os trabalhos atualizam essas questões, sempre em relação aos problemas informacionais.

Wilhelm Peekhaus examina criticamente o modelo capitalista de publicação acadêmica, empregando os conceitos marxianos de "acumulação primitiva" e "alienação". A acumulação primitiva oferece o arcabouço teórico para explicar a apropriação do conhecimento comum que resulta de estratégias utilizadas por editores de revistas acadêmicas capitalistas contemporâneas. O artigo também revela alguns elementos alienantes experimentados pelos produtores de publicações acadêmicas de hoje em dia. Finalmente, propõe uma alternativa para o controle capitalista sobre o campo da publicação científica, com base em projetos de acesso aberto.

Rodrigo Moreno discute a contradição entre informação e conhecimento com base na noção de intelecto geral desenvolvida por Marx nos Grundrisse. O autor demonstra 
como a privatização da produção social do conhecimento é um processo contemporâneo à gênese do capitalismo, tornando-se mais aguda em nosso tempo, precisamente quando o conhecimento se torna o principal fator na produção de riqueza.

Já Figueiredo e Bolaño analisam a passagem da economia política da indústria cultural para a das "novas mídias" com a intensificação da colonização do mundo da vida pelo sistema (Habermas) e com a mudança da sociedade disciplinar para a sociedade de controle (Deleuze). Este processo envolve um refinamento da articulação entre a função econômica da publicidade, a função política da propaganda e a função cultural da programação, com a substituição da última pela interatividade.

Bianca Rhian estuda a relação entre o desenvolvimento das tecnologias da informação e seus fluxos com as necessidades de reprodução ampliada do capital, em face da queda global da taxa de lucros que começou na década de 1970. Ela também demonstra a função econômica, ideológica e cultural da informação como elemento legitimador da política neoliberal, que se apresenta como um sortilégio universal, enquanto na prática revela-se como uma imposição do capital, que gera acima de tudo a agudização da exploração e da desigualdade. A autora também critica a perspectiva positivista da neutralidade axiológica e, portanto, política de ciência.

Carla Viola propõe uma reflexão audaciosa sobre a luta de classes, tendo como um dos componentes conceituais de seu ponto de vista o conceito de individuação, de Gilbert Simondon. Será possível encontrar no conceito de individuação, de Gilbert Simondon, uma relação com Marx e o pensamento marxiano em geral? A autora também analisa o papel da competência crítica em informação em meio à luta de classes.

Os editores convidados do dossiê em questão, Marco Schneider e Ricardo Pimenta, articulam o conceito tomista de verdade, o conceito de história de Benjamin, a alegoria de Camus sobre a peste, a noção de fé de Agnes
Heller e a denúncia do tráfico de escravos de Castro Alves, para criticar o fenômeno da pósverdade, como um renascimento de práticas informacionais fascistas em uma nova ambiência sociotécnica.

Ivan Capeller apresenta um estudo original sobre a lenda do Gólem, baseado em uma leitura de Walter Benjamin, centrada nas relações que este estabelece entre mito e alegoria. Capeller recomenda que se pense na concepção de Benjamin de "alegoria" não só como um objeto relevante de estudo em si, mas também para a compreensão da relação mais ampla entre conhecimento e linguagem.

A reflexão de fundo de Gustavo Saldanha é sobre linguagem e poder. $\mathrm{O}$ autor estabelece um diálogo erudito entre Bakhtin - para quem o signo linguístico é uma arena da luta de classes, antecipando a noção de Bourdieu de que a luta de classes é também uma luta de classificações - e outras filosofias da linguagem. Saldanha discute ainda o problema da pós-verdade, quando a informação é em grande medida mediada por algoritmos "inteligentes".

Sylvia Moretzsohn desvela a especificidade autoritária da constituição capitalista do sistema de comunicação no Brasil durante a Ditadura Empresarial-Militar. Para tanto, explora a noção de "cultura do silêncio", baseada nas reflexões de Paulo Freire sobre os sermões do padre Antônio Vieira (século XVII), assim como algumas ideias de Álvaro Vieira Pinto, em sua crítica ao determinismo tecnológico.

Para Michael Eldred, as relações sociais capitalistas são não só alienantes, mas igualmente uma maneira de viver no mundo globalizado, que pode ser hermeneuticamente pensada como um "jogo lucrativo", para quem sabe vencê-lo. Considerando-o por uma visão filosófica que permite aos atores sociais lutar contra ela em busca de uma interação social livre e justa, Eldred sugere que esse tipo de releitura é necessária para um mundo cibernético cada vez mais invasivo e atraente.

Como os autores desta resenha são os organizadores do dossiê em pauta, esta resenha é em parte calcada no texto original da própria apresentação do dossiê, escrita e 
publicada por nós, originalmente em inglês. Rafael Capurro, autor de referência na área. Pretendemos com essa versão adaptada Serve assim como uma chamada à leitura em português tornar mais acessível aos crítica pela comunidade acadêmica, crítica estudantes e pesquisadores da Ciência esta que os organizadores do dossiê e autores da Informação brasileira uma produção desta resenha aguardam ansiosamente, no internacional organizada por seus pares, a sentido de ampliarmos o debate em torno do convite do criador e editor chefe da IRIE, conjunto de questões abordadas. 